\title{
A Study on the Historical Source and Regional Characteristics of Yimeng Yunjian
}

\author{
Lijuan Feng \\ Linyi University Feixian Campus \\ Feixian, China 273400
}

\begin{abstract}
Yimeng Yunjian is an important part of China's traditional folk costumes. Its tailoring methods, totem implication, color arrangement, and embroidery craftsmanship embody rich connotations and creative ideas. It conveys the unique history and culture, folk customs, and humanistic spirit of the Yimeng region, carries the people's longing for and pursuit of a better life and presents a rich array of artistic features and implications.
\end{abstract}

Keywords-Yimeng; Yujian; history; regional characteristics; folklore value

\section{INTRODUCTION}

Yunjian, also known as "shawls" and "lotus cloth" in folks, is the circular accessories worn by Yimeng women when they were married in old day. Because the embroidered patches on it are mainly quadrilateral cloud patterns and it is embroidered with colorful patterns, surrounded by colored tassels, beads, bells, etc., making the bride who wears it on shoulder walk as the clouds reflecting the sun and the sky glows, it gets the name "Yunjian".

\section{THE Historical SOURCE OF YIMENG YUNJIAN}

The cloud shoulder originated earlier in the history of folk costume culture in China. According to the existing image data, as early as in the Southern and Northern Dynasties, the rudiment of Yunjian has emerged in the clothing of Buddha image in the Mogao Grottoes in Dunhuang. During the Tang and Song dynasties, "five clouds coat" was popular among the women from the upper class aristocratic society and they liked to drape Yunjian. During the Yuan and Ming dynasties, Yunjian gradually spread from the upper class to the folk and became popular everyday clothes. "History of Yuan- record of official garments" has recorded: "Yunjian, made as four vertical clouds, with green edge, five yellow colors, is embedded with gold". It can be seen at that time the production process of Yunjian has been very exquisite. Up to the Qing Dynasty, the production skills of Yunjian were more mature and the decoration was more refined and beautiful. In the early Qing Dynasty, Yunjian were usually satin-embroidered, with 4 fans and 27 pieces. The embroidered pattern was dominated by flowers, birds, beasts, and geometric patterns. There were a small number of characters between them, and the embroidered pieces were connected by string beads. The embroidery skill can be seen everywhere. In the late Qing
Dynasty, the craft of Yunjian reached its peak period, and the folk artificers embroidered Yujian into 4 fans and 32 pieces. In addition to the traditional flat needles, pick needles, and seed-embroidered needles, there were also gold plates and silver plates, draw benching, batch line and so on. The embroidery pieces are decorated with gold and silver threads and beaded beads, with tassels, beads, and silver bells attached underneath. During this period, the theme of embroidery on Yunjian was more extensive than that of the previous period. In addition to common flowers, birds and geometric patterns, character stories, historical legends, deities, and beasts were involved. Until the Republic of China, due to unstable social conditions in the current situation, people's lives were greatly affected and the production process of Yunjian became simpler. The material was changed from silk and damask to cloth and paper trays, and the structure was simplified to 16 or 12 pieces. Embroidery is connected by line instead of bead. The embroidered patterns are mostly auspicious patterns such as flowers, birds, worms and fishes, with big flowers and large leaves, so it is called "a flower of the Republic of China." Many of them are poorly made while few are finely made. The overall level of craftsmanship has declined compared with the Qing Dynasty. After the liberation, with the development of society and the change of people's clothing concepts, the shoulders of clouds have gradually withdrawn from people's daily lives, and have become one of the leading performe.rs in traditional opera costumes.

In Yimeng region, the emergence of Junjian craft started around the Yuan and Ming Dynasties. It was widely popular in the late Qing Dynasty and the Republic of China and became standing clothing for folk women when they married. From the early days of the liberation to the founding of the People's Republic of China, there were still a small number of people who can embroider in Yishui, Yinan, Junan, and Feixian in Linyi city. During the Cultural Revolution, Yunjian were listed as the object of "Breaking the Four Old" and destroyed devastatingly, so its craftsmanship has been lost. However, there are still a lot of beautiful Yunjian in the world. Among them, a Yunjian of Qing Dynasty collected in the Fei County Cultural Center is a relic of the local baron of Laizhuang. Its structure is composed of four large, medium and small twelve pieces cloud patterns, which are sewn with light green, scarlet, and light yellow brocade. The cloud heads are connected by silk string pearls, with dark eight immortals (the artifacts held by Taoism in the Eight 
Immortals) and pattern of flowers, birds, and insects are embroidered. It is adorned with colored tassels all around, and five white jades are adorned underneath, with silver bergamot and small bells dotted in it. The whole Yunjian uses exquisite material, with exquisitely decoration and propitious implication. It is an important representative work of Yunmeng craft in the Qing Dynasty.

\section{REGIONAL CHARACTERISTICS OF YIMENG YUNJIAN}

\section{A. Meaning of the Theme}

The creative theme of Yimeng Yunjian follows the creative rule of Chinese traditional folk art "the picture must have meaning that must be auspicious". Its performance content involves the God and Buddha, beasts, figures, landscapes, flowers and birds and various geometric symbols, etc. It mainly uses the combination of different images to express different auspicious meanings and entrust hopes and aspirations of people for a better life. The extremely broad "Ruyi" cloud pattern in Yunjian is a symbol of "everything is satisfactory, auspicious and well-being". It also implies that draping the Yunjian on body means "satisfaction for the whole life" and the happy blessings from now on. The silk thread in the embroidery pieces of Yunjian is linked to the beaded, which means "combination of beads and jade", and peaceful wedding life. In the design of motifs, the common themes of Yimeng Yunjian include destroying evil spirits, praying for good fortune and baby, wishing marriage, etc. For example, they use the "Clear Eight Immortals" character totem to drive disasters and evils, making nature's various demon stay away from the world and praying for peace, happiness, and satisfaction; with the help of peony, lotus, plum blossoms and other flowers, they imply peace and good fortune in the four seasons, and the spring of the world; with the help of the endless knot, and " $\longleftarrow$ " character lines, they pray for good luck continued. Because of its specific wedding use, Yunjian have also been endowed with rich meaning of reproduction, becoming a symbol of "peaceful couple, many children and more happiness". For example, there are the "phoenix crossing Peony" composed of phoenix and peony, "continue to bear children" composed of the lotus flower, children and the unicorn pattern, and "Large and Small Melons" composed of the watermelon and butterfly pattern. In addition to commonly used auspicious patterns, Yimeng Yunjian often use different combinations of numbers and structures to imply auspiciousness. For example, they use the double-opened Yunjian as a symbol of "blessing and longevity, and double happiness" and use the square Yunjian to symbolize "anything goes well". 27 pieces of willow-style Yunjian means "everything continues for 10,000 years" and so on.

\section{B. Artistic Features}

As an important part of traditional folk costumes in China, Yimeng Yunjian are rich in connotation and ingenious ideas in their methods of tailoring, totem, color arrangement, and embroidery techniques. In the way of production, it adopts the production form of threedimensional tailoring according to different people, and through the hollow connection between the silk thread between the embroidery pieces and beaded, the thick decorative symbols in Yunjian are ingeniously decomposed, avoiding the effect of being not tight due to the material stiffness. It has formed the perfect form and rich meaning of "combination of virtue and reality" and "perfect pair." In terms of structure, Yimeng Yunjian have double-open, square, eight sided, stacked, collared, and collarless, etc. The structure is centered on the neck and is arranged in a radial or rotating skeleton to reflect the worship to the sun and to symbolize the four direction (East, South, West and North) and eight festivals (Spring Festival, Lantern Festival, Ching Ming Festival, Dragon Boat Festival, Tanabata Festival, Mid-Autumn Festival, Chongyang, Laba), which conforms to the creative idea of "All Sides Auspicious". Among them the more common ones are " $x$ " shape, rotating radial shape, and " $\mathrm{m}$ " shape. In the specific design, the embroidered pieces of Yimeng Yunjian are mainly in ruyi-style, willowstyle and lotus-style. The inner embroidery is the various types of beautiful flowers and birds, figures, with the mosaic lace on the outer edge. Its form is beautiful, and the lines are smooth. Each Yunjian have their own themes, but they are all connected to the good wishes and expectations of love and marriage. Taking the example of the common "four-inwish" Yunjian, its overall structure is " $\times$ " shaped, and the embroidery piece is composed of four (12-32) cloud patterns of "Ruyi" with different sizes and shapes. Embroidery patterns are different, and the theme content is also different. For example, embroidering the flowers of four seasons including plum, orchid, bamboo, and chrysanthemum in the cloud pattern symbolizes the progression of seasons and peace for the whole year; embroidering pomegranates, lilies, lotus flowers, and goldfish in the four positions of the " $x$ " shape symbolizes the harmony between husband and wife for centuries, more children and more blessings; embroidering bats, deer cranes, and bergamot, etc. in the above four directions means luck, wealth, long-lived and happy and so on. In the color design, Yimeng Yunjian inherits the "five-color concept" of the folk tradition in China, and incorporates the color customs peculiar to the Yimeng region. Red, blue, yellow, white, and black are the main colors, with bright pink and green, royal purple, gold and silver, etc. as decoration, and black or blue purple as edge, forming a bright and elegant color visual effects. In the local folk, when the bride is married, she wears a red dress. In the red tones of the whole body, the rich color levels of Yunjian, with the strong contrast of the pomegranate skirts makes the celebration of wedding particularly prosperous and full of vitality. In terms of decoration techniques, Yimeng Yunjian are decorated with beautiful embroidery patterns and beaded beads. They are also decorated with colorful long ribbons, tassels, beads, and silver bells and so on. When the bride walks with Yunjian, ribbon and tassels wave with it and beads and the silver bells are also buzzing like a piece of poetry and painting flowing with the wind, with a unique ornamentation and rhythm.

\section{Folklore Value}

Yimeng Yunjian, with its quirky designs, unique tailoring styles, beautiful shapes and romantic humanistic emotions 
have had an important influence in the lives of local people and become a treasure in Yimeng folk costume culture. In the old Yimeng region, when girls grow to eleven or two years old, they need to study needlework at home. The mother asked the village's ingenious people to cut out tricks and teach them to embroider Yunjian at home. In addition to normal meals and schedule, they do not leave the embroidery pieces wherever they go. It usually takes three to five years to finish embroidering, and then use colored string beads to sew four to eight streamers, or to add collars, tassels, beads, and silver bells and other decorations. When a beautiful Yunjian is embroidered, the woman has grown to fifteen or six years old. She will get married soon, so the Yunjian play its role. As one of the traditional folk wedding dresses, the craftsmanship of Yimeng's Yunjian is quaint and the workmanship is extremely delicate. Each work must cost thousands of days and nights and must be completed in thousands of stitches. It accompanies generations of folk women from the youth to the beginning of love, and eventually into the marriage hall. Its flowers, leaves, insects and fish all convey the ancient marriage customs and folk customs of the Yimeng region. It carries the people's longing for and pursuit of marriage and presents a rich beauty of folk culture. The decorative symbols of Yimeng Yunjian, which are beautiful in appearance and auspicious in meaning, borrow things to symbolize best wishes to love and marital life, or they embody the auspiciousness with numbers and sustenance to express people's feelings of "praying for life and longevity". Every time a young man and a woman are married, the colorful Yunjian gown with beautiful decoration and rich connotation on the bride's body is like colorful rosy clouds, which accompanies the love of the new couple to the new start of their lives. The kind of swiftness and splendour, full of rhythm, satisfying people's visual aesthetic needs, stimulate the enthusiasm and temperature of life at the same time, so that the ordinary years will flow light and color since then and become the most beautiful scene in the eyes of every young woman.

\section{CONCLUSION}

Today, with the development of the times, the local people's clothing concept has undergone major changes. The old Yunjian and embroidered skirts have been replaced by white wedding dresses and various new wedding dresses. Even in Chinese weddings, brides mostly wear cheongsams and Hanfu, etc. Local folk traditional wedding dresses are extremely rare in the present-day Yimeng region. The Yunjian wedding dress that once carried the generations of Yimeng women's blood and emotions has also drifted further along with the passage of time. Only the fine lines and the swaying grace of tassels still remain in people's hearts, becoming an everlasting memory of folk culture.

\section{REFERENCES}

[1] Wang Shanshan, "Study on Folk Yunjian Skills and Folklore Culture" [D]. Jiangnan University. 2012.11. 王闪闪《民间云肩技艺及民俗 文化研究》 $[\mathrm{D}]$. 江南大学, 中国优秀硕士学位论文全文数据 库.2012.11
[2] Li Shan. Research on the Four-in-one Ruyi Yunjian of the Late Qing Dynasty and the Early Republic of China[D]. Beijing Institute of Fashion Technology, 2014. 李姗《清末民初四合如意云肩研究》 [D].北京服装学院, 中国优秀硕士学位论文全文数据库.2014.

[3] Xu Yaping, Cui Rongrong, “Chinese Traditional Folk Ornaments Yunjian” [J]. Decoration, 2005.10. 徐亚平,崔荣荣《中国传统民间 服饰品一云肩》[J].《装饰》, 2005.10.

[4] Xue Zainian, Wang Shanshan, Cui Rongrong, "Influence of Folk Cloud Shoulders and Their Production Skills in Lunan" [J]. Journal of Textile Research, 2013.3. 薛再年,王闪闪,崔荣荣《鲁南民间云肩及 其制作技艺探究》 [J]. 《纺织学报》，2013.3.

[5] Shi Jianping, Wang Xuan, "The Use of Traditional Yunjian Costume Art and the Aesthetic Significance of Decoration" [J]. Silk, 2011.3. 施建平, 王萱《传统云肩服饰艺术的运用与装饰审美意义》[J]. 《丝绸》, 2011.3 